\title{
El efecto de realidad y la política de la ficción. Apuntes sobre el modelo estético de lo politico en Th. Adorno
}

The effect of reality and the politics of fiction. Notes on the aesthetic model of politics in Th. Adorno

Laura Elena Flórez Hincapié

Universidad Johann Wolfgang Goethe de Frankfurt am Main lauraflorez12@hotmail.com

DOI: http://doi.org/10.15366/bp2019.21.011

Bajo Palabra. II Época. No21. Pgs: 185-198 


\section{Resumen}

La relación arte-política fue uno de los puntos teóricos centrales de la escuela de Frankfurt, más reconocido en algunos de sus miembros como Walter Benjamin y Herbert Marcuse. La postura estética de Theodor Adorno, sin embargo, ha sido reconocida por rechazar tal relación directa entre praxis social y praxis artística. Este argumento, sustentado en la interpretación del carácter autónomo del arte contrapuesto al potencial político de la reproductibilidad técnica para la masificación del mismo, dejó a la zaga las reflexiones estéticas de Adorno en el desarrollo de la historia, la crítica y la filosofía del arte contemporáneo. Este punto es el que quiero problematizar aquí. Esto es, pretendo mostrar cómo en la estética adorniana se postula el modelo crítico de la praxis artística como praxis política, tanto que en la Teoría Estética de Adorno puede encontrarse una estética de lo político, idea bajo la cual se construyen gran parte de los discursos actuales sobre arte contemporáneo.

Palabras Clave: Escuela de Frankfurt, Teoría estética, Theodor Adorno, praxis artística, Teoria Critica.

\section{Abstract}

The art-political relationship was one of the central theoretical points of the Frankfurt school, most recognized in some of its members as Walter Benjamin and Herbert Marcuse. Theodor Adorno's aesthetic stance, however, has been recognized for rejecting such a direct relationship between social praxis and artistic praxis. This argument, based on the interpretation of the autonomous nature of art as opposed to the political potential of technical reproducibility for its massification, left Adorno's aesthetic reflections on the development of contemporary art history, criticism and philosophy behind. This is the point I want to make here. I intend to show how the critical model of artistic praxis as political praxis is postulated in the adornian aesthetic, so much so that in the Aesthetic Theory of Adorno an aesthetic of the political can be found, an idea under which a great part of the current discourses on contemporary art are constructed.

Keywords: Frankfurt School, Aesthetic theory, Theodor Adorno, artistic praxis, Critical Theory. 
L a presente reflexión tiene como objetivo contornear las líneas de un modelo político de la estética en el contexto del pensamiento adorniano. Para ello desarrollaré tres puntos. El primero mostrará a grandes rasgos la idea de Adorno de una literatura o de un arte comprometido, en la cual se encuentran algunos de los elementos principales para comprender la relación del arte con la sociedad en el marco estético adorniano. Para ello haré en la segundad parte un análisis comparativo del modelo del arte moderno que utiliza Adorno en esta discusión, a saber, el Guernica de Pablo Picasso, con la obra de arte contemporánea de Gerhard Richter Birkenau Bilder, en la cual el motivo del compromiso del arte en Adorno se concreta en la idea del potencial crítico-político de la imagen. En un tercer momento intentaré utilizar los elementos ganados en el análisis para comprender el rol de una obra de arte contemporánea en Colombia en el contexto socio-político actual. Con ello pretendo configurar la idea de cómo el espacio ficticio que crea el arte es un lugar de lucha política.

\section{La obra de arte comprometida: Guernica de Pablo Picasso}

"Cada una de las dos alternativas se niega a sí misma al mismo tiempo que a la otra: el arte comprometido porque, necesariamente separado de la realidad en cuanto arte, niega la diferencia con respecto a ésta; la de L'art pour L'art porque con su absolutización niega también aquella indisoluble relación con la realidad que la autonomización del arte frente a lo real contiene como su a priori polémico. La tensión de la que el arte ha vivido hasta tiempos muy recientes se desvanece entre estos dos polos."

El discurso sobre la autonomía del arte y su compromiso con la sociedad se entiende en el pensamiento adorniano de una manera dialéctica. Es decir, que la categoría de autonomía es uno de los polos de lo que Adorno comprende como la mediación del arte. Sin embargo, éste no corresponde a un concepto tradicional de la dialéctica, basado en un proceso reconciliado o sintético, sino que toma como punto de partida la contradicción, como único elemento que puede describir los fenómenos sociales. Tanto así que según Adorno la crítica de la sociedad sólo se legitima si sus fenómenos se tamizan primero a través del pensamiento crítico del

1 Theodor Adorno, "Compromiso", en: Notas sobre literatura, Obra completa 11, Madrid, Akal, p. 394. 
investigador social. Desde la perspectiva de la historia del arte, Adorno desarrolla su pensamiento justo en el marco histórico del desarrollo del arte moderno de finales del siglo XIX y el comienzo del XX. Éste es un modelo histórico de tal práctica crítica de la sociedad, o para nombrarlo en términos epistemológicos, del movimiento dialéctico de negación no reconciliada. Puesto que las vanguardias históricas artísticas se fundamentaron en un movimiento meta crítico de la institución artística, base que determinó toda la producción artística de esta época. Esto es, un arte que desde una mirada crítica al desarrollo histórico desde el Renacimiento hasta el Neoclasicismo del siglo XIX introduce un giro en la praxis artística. Éste estuvo caracterizado por la vuelta a una relación entre arte y sociedad, en la cual prima la idea de un compromiso político más evidente en el desarrollo de las vanguardias históricas a principios del siglo XX.

En este clima artístico, y en consonancia con la sociología de Durkheim, Adorno concibe que la obra de arte presenta tensiones que también expresan las tensiones de la sociedad. En definitiva, la autonomía del arte como categoría se reconoce con la emancipación del sujeto burgués, puesto que con el surgimiento de la sociedad burguesa se integra con ella la idea de libertad en el sujeto racional, esto es, se comprende la idea de un sujeto emancipado como un sujeto racional que puede darse a sí mismo leyes para el actuar moral, sin la coacción de fuerzas externas a su consciencia. Esta concepción de la libertad del sujeto burgués es históricamente falseada, es decir, en el desarrollo de la modernidad occidental, la historia ha demostrado que este ideal de "autonomía" o de "libertad" es falso. Según Adorno, este ideal de libertad no se corresponde materialmente con la realidad empírica de los seres humanos, llegando esta contradicción históricamente a momentos tan extremos como el de Auschwitz. Una comprensión de la idea de libertad como ésta se encuentra anclada en una concepción materialista de la libertad, la cual determina que ésta comienza por la libertad del cuerpo, el primer elemento reificado y sometido del desarrollo de la razón instrumental.

Este nivel material del ser humano ha sido asimismo tematizado en el desarrollo del pensamiento occidental a través de la Estética, la cual lo ha limitado a la reflexión sobre el arte y la capacidad artística. Este escollo en la reflexión de la importancia del cuerpo para determinar la existencia humana es precisamente el punto en el que Adorno ancla su reflexión estética. El concepto de autonomía lo ubica Adorno desde la perspectiva de las vanguardias históricas. Esto es, él concibe la autonomía del arte desde una perspectiva dialéctica - como lo mencioné anteriormente -, en la cual el arte es autónomo en la medida en que es consciente de su historicidad, esto es, de cómo se encuentra normativamente anclado en un contexto social, espacial y político determinado. Esto se debe a que el movimiento inmanente de la obra 
corresponde a la oposición de la sociedad, y según el argumento de Adorno, ésta es la naturaleza normativa del arte: "Socialmente, el arte es su movimiento inmanente contra la sociedad, no su toma de posición manifiesta. Su gesto histórico expele la realidad empírica, a la que las obras de arte pertenecen en tanto que cosas. Si se le puede atribuir a las obras de arte una función social, es su falta de función”. ${ }^{2}$

Esta dinámica la ubica el pensador frankfurtiano a través de la reinterpretación crítica de las categorías de autonomía y expresión. Y la relación entre ambas categorías quiero explicarla desde una obra concreta, a saber: el Guernica de Picasso. Guernica fue la obra encargada a Picasso por el Estado Español para la Exposición Universal de 1937 en París. Es de todos conocido que en el proceso de concepción de la obra ocurrió el devastador bombardeo en la ciudad vasca de Guernica en el mismo año de la exposición (1937), y que fue este el motivo elegido por Picasso para su pintura. Dado lo famosa que es esta pieza, no voy a detenerme aquí en una digresión acerca de su contexto, sino que pasaré de inmediato a los elementos que me interesan. En 1962 Adorno expuso la discusión "Engagement oder künstlerische Autonomie" (Compromiso, o la autonomía artística) en la emisora de Radio Bremen, la cual fue publicada en 1965 en el tercer tomo del libro "Notas sobre literatura". En ella cita Adorno la famosa anécdota del oficial alemán que visita el taller de Picasso en París: "Cuando un oficial del ejército alemán de ocupación le visitó [a Picasso] en su taller y ante el Guernica le preguntó: «¿Ha hecho usted esto?», respondió: «No, ustedes». Incluso obras de arte autónomas como ese cuadro niegan en definitiva la realidad empírica, destruyen la realidad destructora, lo que meramente es y en cuanto mero ser-ahí repite infinitamente la culpa". ${ }^{3}$

La discusión sobre el arte comprometido tiene su contexto en la interpretación adorniana del arte autónomo. Autonomía es una de las categorías típicas de la estética. Ésta se sistematiza con Kant, pero es acuñada como disciplina filosófica con Baumgarten en el siglo XVIII. La idea de autonomía del arte de Kant se interpretó posteriormente en la autonomía como aislamiento de la obra de arte de la praxis social, lo que apartó tanto la producción como la experiencia estética de cualquier tipo de compromiso social. Adorno, heredero del giro crítico que con las Vanguardias históricas del siglo XX experimentó esta categoría, sostiene contra esta idea de autonomía uno de los postulados sociológicos del arte - ya establecidos desde Durkheim - a saber: que el arte es un fait social. Así, Adorno historiza esta categoría de autonomía y la convierte en un concepto dialéctico con el cual se puede entender la obra de arte como un objeto autónomo de la sociedad, gracias a su forma que es

\footnotetext{
2 Theodor Adorno, “Sociedad", Teoría Estética, Akal, Madrid, pp. 297-345.

3 Theodor Adorno, Notas sobre literatura, Op. Cit., p. 408.
} 
capaz de transformar la materia en un espacio ficticio; y a la vez como un objeto heterónomo, en tanto esta forma no sólo existe como hecho real, sino que toma su contenido de la sociedad y a través de su forma autónoma la expresa como crítica. Esta idea de una "autonomía heterónoma" o la dialéctica entre autonomía y fait social de las obras de arte, la comprende Adorno a través del concepto de Expresión, otra categoría estética central en el desarrollo del pensamiento occidental.

Este doble movimiento a través de la idea de Expresión lo capta Adorno en el Guernica de Picasso. Dice Adorno en la Teoría Estética: "El criterio central es la fuerza de expresión mediante cuya tensión las obras de arte hablan con un gesto sin palabras. En la expresión se revelan como cicatriz social; la expresión es el fermento social de su figura autónoma. El testigo principal de esto sería el Guernica de Picasso, que con su estricta incompatibilidad con el realismo prescrito, mediante su construcción inhumana, adquiere esa expresión que lo agudiza como protesta social más allá de todo malentendido contemplativo". "El arte es social por mor de su capacidad de autonomizarse de la sociedad en la que surge. Esta autonomía, en otras palabras, es en Adorno la distancia crítica que el arte logra de la sociedad, su posibilidad de distanciarse y hacer de este un movimiento, de manera simultánea un movimiento de la mirada del espectador no sólo hacia la obra, sino hacia sí mismo.

\section{El efecto de la realidad: las imágenes a pesar de. "Birkenau Bilder" de Richter}

Entre más distante Sea el arte de la sociedad, más político es. Podría uno resumir en una frase como ésta la concepción del arte comprometido en Adorno. Pero lo que ha de enfatizarse es que aquella "distancia" o "autonomía" se refiere a la fuerza crítica que vive en las obras de arte (o en últimas, en el potencial estético del hombre). Lo que Adorno — según mi interpretación — critica de la concepción de compromiso de Sartre —además del realismo de Lukács — es la cercanía de este concepto de compromiso con el de realismo. Pues el objetivo de la obra de arte no es representar el efecto de la realidad sino politizar ésta en el espacio de la ficción, como el título de mi reflexión señala. Para comprender esto utilizaré una de las obras de arte contemporáneo alemán más pregnantes de los últimos años, la serie de pinturas de Gerhard Richter "Birkenau" de 2014. Esta obra surge a partir del descubrimiento de unos negativos fotográficos encontrados bajo tierra en el crematorio V de uno de los campos de exterminio de la Alemania Nazi: Auschwitz,

4 Theodor Adorno, Teoría Estética, (Traducción de J. Navarro Perez), Obra completa 7, Madrid, Akal, 2002, p. 314. 
Birkenau. Estos fueron hallados escondidos en un tubo de pasta dental, enterrada, y de ellos pudieron revelarse cuatro fotografías. La cámara fotográfica fue contrabandeada por la resistencia judía en el verano de 1944 y con ella, dos integrantes del Sonderkomando tomaron las imágenes. Uno vigilando los guardias del SS desde el techo del crematorio $\mathrm{V}$-que debía ser reparado ya que entre mayo y junio de este año fueron gaseados aprox. 435.000 judíos húngaros (24.000 por día)- y el otro tomando las imágenes desde una de las barracas en las que dormían.

Cuatro imágenes quedan del "infierno" del campo de exterminio. Una de las imágenes revela el camino a uno de los hornos crematorios de lo que parece ser un grupo de mujeres, otras dos revelan la limpieza de las cenizas del horno y de los cadáveres recién gaseados a plena luz del día y la otra es una imagen casi abstracta, cuyas condiciones de captura a contraluz dieron como resultado una imagen sobreexpuesta, la cual sólo deja distinguir la copa de un árbol. El ángulo indica el trabajo clandestino de los fotógrafos, quienes junto al rollo de negativos dejaron una nota en la que se atestiguaba este acto. Dado los límites de la presente ocasión no puedo detenerme en los interesantes detalles de estas fotografías, por lo que me interesa pasar a la obra de Richter directamente.

Richter se entera de la existencia de estas fotografías gracias al comentario de Georges Didi-Hubermann. A partir de allí se propone hacer cuatro pinturas con ellas, utilizando su técnica: la pintura sobre imágenes fotográficas. En una entrevista al Frankfurter Allgemeine Zeitung declara Richter que: "En el otoño de 2014 empecé a calcar estas imágenes sobre el lienzo y me di cuenta pronto que definitivamente no funcionaba. Entonces taché y pinté nuevamente sobre lo tachado, tanto, que obtuve cuatro imágenes abstractas. Este procedimiento no es inusual: es decir, comenzar objetualmente y aterrizar en la abstracción". ${ }^{5}$ Las cuatro pinturas son imágenes abstractas en blanco y negro, con manchas rojas y verdes. Este acto de iniciar con la reproducción de las imágenes y en el proceso artístico responder a la exigencia del material configura una interesante constelación con respecto a nuestro tema. El efecto de la verdad histórica, de los hechos de los que la obra parte exige la creación de un espacio ficticio en el que aquella realidad es reelaborada a través de la forma artística y con esta se transmite como testigo de la historia, como representación de lo irrepresentable, como infinita exhibición de la culpa. Y aquí resuena precisamente uno de los tópicos adornianos más polémicos, y es la idea de

\footnotetext{
${ }^{5}$ Als ich das Buch gekauft habe, sah ich, dass es vier Bilder sind, und da entstand dann die Idee, das doch zu malen - trotz meiner Zweifel, dass das funktionieren würde, dass ich durchs Abmalen „Bilder“ erzeugen könnte. Im Herbst 2014 fing ich an, diese vier Bilder auf die Leinwände zu übertragen und merkte bald, dass es nicht geht. Also abkratzen und neu malen, solange, bis ich die vier abstrakten Bilder hatte. Dieser Vorgang ist nichts Ungewöhnliches, also gegenständlich anfangen und abstrakt landen“.
} 
la imposibilidad de representar lo ominoso, o de la imposibilidad de hacer arte después de Auschwitz, la cual como quiero plantear en la siguiente conclusión, no se refiere a un "final del arte" en un sentido literal, sino a un cambio en el paradigma de la praxis artística.

\section{La política de la ficción: la imagen como testigo. Requiem N.N. de J.M. Echeverría}

LA IMAGEN COMO TESTIGo es la función de una imagen que trasciende su momento histórico y nos es legada como una mirada, en primera instancia, "sin mediación" (por su efecto) hacia el pasado. Esta distancia es la posibilidad de que estas imágenes funcionen como medio crítico de transmisión de la historia, y en este caso concreto, a través de dos formas. La primera, el uso del medio fotográfico como forma de documentación. La segunda, la representación artística (institucionalizada) de esta realidad ya vuelta ficción. Porque sólo como ficción nos llegan los acontecimientos de la historia, y su transmisión está sujeta a diversas formas de narración. Las líneas finales de la Teoría Estética de Adorno parece ser la redefinición de esta función de la imagen como testigo, la cual sería una de aquellas posibles maneras de narrar la historia: “...pero sería mejor que algún día el arte desaparezca a que olvide el sufrimiento que es su expresión y en el cual la forma tiene su sustancia. (...) Qué sería del arte como Geschichtsschreibung ('escritura de la historia') ${ }^{6}$ si se quitara de encima la memoria (Gedächtnis) del sufrimiento acumulado". ${ }^{7}$ Precisamente la idea del arte como "escritura de la historia", como anamnesis de lo reprimido, de lo anulado, es uno de los vértices de la crítica de arte contemporáneo.

Si comprendemos la obra de Richter como este ejercicio de anamnesis, podemos establecer un modelo con otra obra contemporánea, en este caso una obra del artista colombiano José Manuel Echavarría. En la instalación de fotografías Requiem $N N$ de José Manuel Echavarría asistimos a un ejercicio análogo a los dos comentados anteriormente. Echavarría recorre una región de Colombia llamada Puerto Berrío, anclada a las orillas del río Magdalena, condición por la cual ésta fue una

\footnotetext{
${ }^{6}$ El traductor al castellano traduce "historiografía" lo cual no corresponde al sentido de la argumentación de Adorno. Historiografía en alemán corresponde a la palabra "Historiographie" la cual se refiere a la ciencia histórica de recolección y narración de datos. Por su parte la palabra "Geschichte" se refiere a la historia como concepto, en el caso de la filosofía de Adorno, carga con toda una tradición dialéctico-materialista que es la que está en juego en este pasaje clave de la Teoría Estética. Adorno, Th., Teoría Estética, Op. Cit., (p. 343).

7 Adorno, Th., Teoría Estética, Op. Cit., p. 343.
} 
zona de importante influencia paramilitar y guerrillera durante más de 30 años. Echavarría inicia un trabajo de campo en esta zona por primera vez en el 2006, en la cual observa un ritual bastante particular. Dada la importancia del río, un gran porcentaje de la población vive de la pesca, y mediante esta actividad durante ańos ha enfrentado el conflicto colombiano de manera directa: junto con los peces, la atarraya sacaba del río cadáveres o partes de cadáveres que bajaban por su cauce. La comunidad entonces decide enfrentar esta realidad a través de un rito: rescatar los cuerpos de los NN, e incluso los fragmentos de cadáveres, y darles cristiana sepultura. Esta práctica comienza a extenderse en el pueblo, de manera tal que cada habitante escoge un NN y lo adopta. Esta adopción va desde el bautizo del NN, hasta cubrir los gastos del entierro, entre lo que se incluía el cuidado y ornamentación del osario. A cambio, el NN ESCOGIDO hace "favores" o "milagros" a su familia o persona adoptiva, y en tanto más decorado y cuidado el osario del NN, tantos más favores o milagros concebidos al adoptante.

La obra de Echavarría se compone entonces de las fotografías de estos osarios, y posteriormente de la investigación y exhibición de este fenómeno a través de un documental. Bien puede observarse en este caso una analogía con la obra de Richter, en tanto a través de la imagen el medio artístico permite construir un espacio ficticio de reconocimiento en este caso no solo de la práctica religiosa, antropológica y cultural en la que la comunidad se involucra como reacción a la ominosa presencia de la violencia en su entorno cotidiano, sino que evidencia uno de los fenómenos más trágicos del conflicto colombiano: la negación no solo de la vida, sino del cuerpo. A través de esta obra, sin embargo, la realidad y el efecto de su presencia son exhibidos por la imagen, no como una reproducción literal del terror que la aparición de un cadáver produce, sino la aparición de un espacio de ficción que permite elaborar criticamente esta realidad social. Este espacio ficticio es en este caso el espacio de la memoria, la cual a través de la expresión de la obra de arte hace que aquello suprimido en la historia del conflicto se adelante a la experiencia de percepción de la obra. La imagen de estas lápidas que cubren los osarios, sus distintivos, flores, nombres, imágenes, colores; su composición espontánea que raya en una imagen $p o p$ nos remite como espectadores a un episodio de tortura, de negación del cuerpo no solo como asesinato sino como una condena, que le dicta al difunto la imposibilidad de ser reconocido por su familia y medio social, así como a su familia de no elaborar un duelo para su pérdida.

Un modelo político de la estética en Adorno es el imperativo del uso del material artístico como memento: "La expresión -dice Adorno en su Teoría Estéticacon la cual la naturaleza se cuela en el arte, es al mismo tiempo su aspecto no literal, el memento de lo que la expresión misma no es y de lo que no se concreta de otra 
manera que mediante su cómo". ${ }^{8}$ Esto es, como memoria, como anamnesis de lo suprimido en el curso de la historia, pero que permanece sedimentado tanto en el individuo como en la colectividad. Esto sedimentado se manifiesta de diversas maneras: por medio del trauma, en las expresiones inconscientes de violencia e intolerancia, en la repetición inconsciente de patrones sociales de comportamiento y organización, por citar algunos ejemplos. A través de la capacidad estética puede elaborarse esto reprimido a través de la construcción de objetos que no se comprenden como un reflejo literal de la realidad como su espejo, sino que más bien funciona como la imagen en un espejo que se vuelca hacia el espectador y su acervo socio-cultural. Esto remite a la ya antigua fábula que inauguró el discurso del arte o la estética, en la cual en el concurso entre los pintores Zeuxis y Parrasio por la pintura más realista, Zeuxis pintó un racimo de uvas tan idéntico con la fruta, que al destapar el cuadro los pájaros vinieron a intentar comerlas. Zeuxis le pidió entonces a Parrasio que corriera el telón de su pintura, tan sólo para que Parrasio revelara que la cortina en sí era una pintura, y Zeuxis se vio obligado a conceder la victoria a su oponente. Esta fábula nos ayuda a concretar la que Adorno entiende como la tarea del arte: el arte no imita la naturaleza, imita la experiencia de lo bello natural. En esta fábula se cuela desde el Siglo V a.c. la que hoy parece ser la base de la experiencia del arte contemporáneo: la tarea crítica del arte. Una valiosa cita de esta escena la hizo Ad Reinhart en 1942 al describir cómo mirar una pintura cubista: la obra de arte contemporánea permite que el espectador reconozca a través de su contemplación su propia heteronomía, esto es, que él también es un espacio histórico.

El artista abre un espacio crítico para teorizar y experimentar estas acciones no sólo para sus protagonistas, sino también para un público presente y futuro, sacando a la luz estas imágenes como testigo. Llamo a este ejercicio, de la mano del pensar estético de Adorno, "producción de imágenes ominosas", las cuales son una solución estética de posiciones éticas difíciles en relación con fenómenos históricos. Es decir, un tratamiento de la historia con un punto de vista ético determinado por la expresión estética. La idea de la imagen como "recuerdo" corresponde a este uso de la imagen como medio de representación crítica de la historia, la cual permite presentar un "testigo" del horror. Georges Didi-Huberman lo describe como el "acto pictórico", como la descripción imposible de un hecho histórico arrancada de la realidad.

En este caso, se puede observar una analogía de la obra de Echavarría con la obra de Richter, ya que el medio artístico permite que la imagen construya un espacio

${ }^{8}$ Ibid., S. 156. 
ficticio de reconocimiento, no sólo de las prácticas religiosas, antropológicas y culturales en las que la comunidad se involucra en respuesta a la presencia amenazante de la violencia en su entorno cotidiano, sino también de uno de los fenómenos más trágicos del conflicto colombiano: la negación no solo de la vida, sino también del cuerpo. Sin embargo, a través de la obra, la realidad y el efecto de su presencia se muestran en las imágenes de las lápidas, no como una reproducción literal del horror causado por la aparición de un cadáver, sino como la aparición de un espacio de ficción que permite observar críticamente esta realidad social. En este caso, este espacio ficticio es el espacio de la memoria que, a través de la expresión de la obra de arte, hace que lo que ha sido suprimido en la historia del conflicto se presente en la experiencia de la percepción de la obra. La imagen de estas placas conmemorativas que cubren los osarios, sus peculiaridades, flores, nombres, cuadros, colores; su composición espontánea, parecida a un cuadro pop, nos envía como espectadores a un episodio de tortura, negación del cuerpo no sólo como asesinato, sino como sentencia que dicta al difunto la imposibilidad de ser reconocido por su familia y su grupo social, así como de que su familia no haga duelo.

Es este acto de negación del entierro a través de la desaparición de los cadáveres torturados y asesinados lo que constituye el núcleo de la expresión crítica de estas obras, y es el lugar en el que se configura lo que he tratado de abordar en este texto como un elemento ético de la estética. Esta idea fue esbozada por el pensamiento estético de Theodor Adorno, en el que el ejercicio del investigador social se entiende como un ejercicio interdisciplinario, es decir, como un ejercicio en el que no solo está involucrada la esfera del concepto y la razón a nivel epistemológico, sino en el que la capacidad estética y la acción ética y moral del hombre convergen con igual significado. Así, la práctica artística ofrece una solución estética para la forma de narración del análisis de los fenómenos históricos a través de la imagen. La imagen es entonces así entendida como un "acto". Un fenómeno social como la desaparición violenta de la población civil por parte de la guerrilla, pero también por parte de los ejércitos paramilitares como en el caso de Colombia, encuentra una narración crítica en las imágenes de la obra de Echavarría.

Esta es la tarea de un arte comprometido para Adorno, es decir, no imitar literalmente el estado de cosas reales a través de la representación del arte, sino la creación de un simulacro, de un espacio ficticio en el que aquella realidad se elabora como un espejo en el que cada espectador puede cuestionar críticamente su posición en la historia. Como las imágenes de Restrepo evidencian el sufrimiento de las víctimas del conflicto colombiano, o las imágenes de Richter erigen una contra-memoria de uno de los episodios más ominosos de la historia de Europa, o la siempre actual Guernica de Picasso. 


\section{CODA}

QUiERo ANOTAR QUE EN SEPTIEMbre del año 2017 fueron colgadas en un acto simbólico y con la presencia de Gerhard Richter en la sala occidental del edificio del Bundestag alemán una reproducción del ciclo de imágenes "Birkenau Bilder", comentadas en este texto. Ahora ellas se encuentran diariamente contra los 92 nuevos miembros del parlamento alemán pertenecientes al AfD (Alternativa por Alemania por sus siglas en alemán), partido de ultraderecha, que representa toda la carga histórica de la Alemania Nacionalsocialista. Imágenes que repiten y recuerdan también la reformulación del imperativo categórico de Adorno de recordar para no repetir. O de evitar que Auschwitz se repita. Esto lo considero arte como crítica social. 


\section{RefERenCias Bibliográficas}

Adorno Theodor, Nachgelassene Schriften. Abteilung IV: Vorlesungen - Band 3: Ästhetik (1958/59), Frankfurt am Main, Suhrkamp, 2012.

- Zur Lehre von der Geschichte und von der Freiheit - (1964/1965), Frankfurt, Suhrkamp, 2012.

- Notas sobre literatura, Obra completa 11, Madrid, Akal, 2002.

- Teoría Estética, (Traducción de J. Navarro Perez), Obra completa 7, Madrid, Akal, 2002.

Bernstein, J.M.; Brodsky, C.; et all, (), Art and Aesthetics after Adorno,

Bürger, Peter, Theorie der Avantgarde, Frankfurt am Main, Suhrkamp, 1974

, „Das Vermittlungsproblem in der Kunstsoziologie Adornos“. In: Linddner, Burhardt und Lüdke Martin, (Hgs), Materialen zur Ästhetischen Theorie Th. W. Adornos: Konstruktion der Moderne, Frankfurt am Main, Suhrkamp, 1980

, „Kunstsoziologische Aspekte der Brecht-Benjamin-Adorno-Debatte der 30er Jahre“. In: Bürger, Peter, Seminar: Literatur und Kunstsoziologie, Frankfurt am Main, Suhrkamp, 1978.

Didi-Hubermann George, Imágenes pese a todo. Memoria visual del holocausto, Madrid Paidós.

Roberts, David, Art and Enlightment. Aesthetic Theory after Adorno, University of Nebraska Press, 1991

Uwe Hohendahl, Pete, the Fleeting Promess of Art, Cornell, Cornell University Press

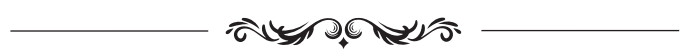

DOI: http://doi.org/10.15366/bp2019.21.011

Bajo Palabra. II Época. No21. Pgs: 185-198 
